\title{
The matters of the heart are the heart of the matter
}

\author{
Nature Cardiovascular Research joins the worldwide effort during the 'heart month' of February to raise awareness on \\ how to prevent cardiovascular disease and make healthy lifestyle choices that lead to better cardiovascular health.
}

ebruary is a month when we celebrate

- love. Hearts and heart-shaped gifts epitomizing love can be seen almost everywhere around the globe, in anticipation of Saint Valentine's day. It is perhaps less well known that in North America and the UK, February is designated as a 'heart month', to remind us how important cardiovascular health is, and what we can do to keep our cardiovascular system healthy. Keeping your heart and vessels in homeostasis - well, that is true love for thyself and those who care about you.

It all started back in December 1963, when the US President Lyndon B. Johnson signed Proclamation 3566, declaring the month of February a time to raise awareness about cardiovascular health, as back then cardiovascular diseases (CVDs) accounted for $50 \%$ deaths in the United States. The proclamation also highlighted how much good for public health can be done when scientists and policy-makers come together.

"Whereas these programs of research and education have resulted largely from the teamwork between the American Heart Association, its chapters and affiliates, and the Federal Government, particularly the Public Health Service through the National Heart Institute and the Heart Disease Control Program; and
Whereas the results thus far achieved in combating the cardiovascular diseases give hope that the continuation and expansion of these programs may eventually eliminate these diseases as important causes of death; and

Whereas it is essential to the health and well-being of our nation that our citizens be made aware of the medical, social, and economic aspects of the problem of cardiovascular diseases, and the measures being taken to combat them; and

Whereas the Congress, by joint resolution approved December 30, 1963, has requested the President to issue annually a proclamation designating February as American Heart Month....

Almost 60 years later, what started as a joint effort of scientists and policy-makers in the United States became much bigger than that - it has become common knowledge worldwide that the risk of CVD can be reduced by a healthy diet, regular exercise and sleep, stress control, and avoidance of cigarette smoking and substance abuse. US President Joe Biden has asked Americans this February to join him "in recognizing and reaffirming our commitment to fighting cardiovascular disease." Although CVD mortality has decreased since 1964, with CVD now accounting for $25 \%$ of deaths in the United States and 33\% of deaths worldwide, the fact remains that CVD is still the leading cause of death globally. Research into preventing, diagnosing and treating CVD is not enough - we need to do more, but how can we do better?

It is obvious that the advances made in our combat against CVD in the past 60 years have been largely initiated in scientific and clinical laboratories, putting cardiovascular scientists at the forefront of our efforts to decrease the global burden of CVD. It is essential that the work of these scientific communities be adequately funded and promoted, and that their findings be efficiently, broadly and quickly disseminated and translated into clinical practice and new health policies. We need to continue to learn about CVD and continue to educate the public about ways to prevent these diseases, recognize their symptoms and ask for professional help that should be available to everyone, regardless of their race, ethnicity, beliefs or socio-economic status.

Nature Cardiovascular Research, a 'newcomer' scientific journal that cares deeply about cardiovascular health, pledges to dedicate all our efforts to this good fight.

Published online: 14 February 2022 https://doi.org/10.1038/s44161-022-00031-X 